\title{
THE DISTRIBUTION SYSTEMS OPERATOR'S ROLE IN ENERGY TRANSITION: OPTIONS FOR CHANGE
}

\author{
ERIKA ZOMERMAN ${ }^{1,2}$, HENNY VAN DER WINDT ${ }^{1} \&$ HENK MOLL $^{1}$ \\ ${ }^{1}$ Energy and Sustainability Research Institute, University of Groningen, The Netherlands \\ ${ }^{2}$ Centre of Expertise Energy, Hanze University of Applied Sciences, Groningen, The Netherlands
}

\begin{abstract}
Distribution Systems Operators (DSOs) are key players in the design and development of a Local Energy System (LES). These systems need to adapt to the fast replacement of fossil fuels by Renewable Energy Sources (RES). With regard to this energy transition, the all-electric system is one of the potentially sustainable, future LESs. However, DSOs face problems in the development of such systems in relation to their role. They wonder how they must adapt their current design process in order to better facilitate energy transition and include values such as participation and the distribution of costs and benefits, which are seen as important by residents and other stakeholders. The purpose of this research is to consider the role of values in the design process of LES by using a value sensitive design method. A case study was set up in a newly built Dutch all-electric neighbourhood using electric heat pumps. Ten semi-structured interviews were held with DSOs' representatives and other experts. The study resulted in a description of the current and desired design process in the light of the DSOs' three core values: reliability, affordability and sustainability. We conclude that these are substantive values that relate to the technological artefact. However, four procedural values appear to be of importance too: participation, communication, trust between parties, and distribution of costs and benefits. A value based design approach for LES enables DSOs to better facilitate energy transition. In order to reach this, DSOs, (urban) planners, policymakers, real estate developers and residents have to cooperate in a transparent way during earlier phases in urban planning. More flexibility in the financial structure of investment and operational costs and benefits is required in order to enable future proof energy systems like all-electric neighbourhoods.

Keywords: energy transition, distribution systems operator, local energy systems, value sensitive design, substantive values, procedural values, design process, all-electric neighbourhood.
\end{abstract}

\section{INTRODUCTION}

The Dutch DSOs' face a changing energy landscape, in which they expect their role to change [1] DSOs have operated on a technical model, based on decades of experience in designing, maintaining and optimising local and regional energy systems. In the Dutch situation, Local Energy Systems (LES) have mostly been hybrid systems that consist of gas and electricity grids. However, the changing domestic energy situation like a growing amount of new energy conversion (e.g. electric heat pumps), generation (e.g. solar panels) and energy intensive technologies (e.g. electric cars), has consequences for the use of the grid(s) and the actors [2] Innovation research has shown that technology co-evolves with institutions, societal actors and policies, eventually forming socio-technical systems [3]. Of the domestic energy use, the households' heating demand is responsible for $14 \%$ of the total Dutch energy demand. A rapid change from a fossil fuel based society to a society that can rely on Renewable Energy Sources (RES) is desired [5], [6]: this energy transition will help to drastically reduce $\mathrm{CO}_{2}$ emissions. In this process of innovation, experimentation and implementation, it is necessary that stakeholders are involved and that there is an intensive exchange of information between stakeholders.

Innovations are pushed by long-term energy policies like the goal to have a "climate neutral energy system" in 2050 as set by the Dutch national government. A balance between reliability, affordability and sustainability of the energy system remains needed [6]. A more 
short-term Dutch regulation is to abolish the DSOs' obligation to realise household gas connections as per July 1st, 2018; this puts even more pressure on the development of more sustainable energy systems. As a result, new and existing houses need to move towards other technologies at a much faster pace than before. In addition to all-electric homes, other options like district heating or hybrid systems are expected to grow. In 2016 almost $94 \%$ of all existing Dutch houses had a connection to the natural gas grid [4], since the gas boiler is the dominant domestic heating device. One of the increasingly adopted technologies for domestic heating is the electric heat pump. In 2017 only 2\% of Dutch households made use of an electric heat pump but this number is expected to increase with $30 \%$ yearly [4]. The heat pump is suitable for well-insulated houses and its heat production is, according to EU guidelines, regarded as renewable energy technology. However, the transition to renewable energy is not without problems.

One reason for the difficulties in the transition is the growing complexity in energy infrastructure planning of new LES: the DSOs foresee a change in their role but are not fully prepared for it. In the search for applying more RES, the balance between the values of reliability, affordability and sustainability of the energy system is an enormous challenge. Acceptance and satisfaction of RES by stakeholders not only depends on the way the energy system meets their requirements, but also on the way they are involved in the design and development process [10]. Current energy system design processes are mainly carried out by DSOs based on technical design criteria, with limited or no involvement of other stakeholders. However, the design of a system in some way needs to relate to stakeholders' values. All Dutch DSOs hold three values that are informally known as "public values". Public values in general can be understood as a framework of principles, rights and obligations that bind a society together. Applied to the energy sector, public values are expressed in terms of reliability, affordability and sustainability. These three values need to be in balance and form the basis of this research. Edens reports that the three values are weighed differently by different parties.

Our research considers the design process of a LES; this design generally takes place in the fourth phase in a typical urban planning process [12] as shown in Table 1. In the second phase the decision for the type of energy carrier (all-electric or else) usually takes place.

Table 1: Typical phases I the Urban Planning Process.

\begin{tabular}{|c|l|l|}
\hline Phase & Urban planning process & Organisation and tasks \\
\hline 1 & $\begin{array}{l}\text { Preparatory / exploration } \\
\text { phase }\end{array}$ & First assessments, basic data, pre-checks \\
\hline 2 & Feasibility / planning phase & $\begin{array}{l}\text { Feasibility of different themes, like mobility, } \\
\text { energy. Masterplan, urban design, contracts, } \\
\text { agreements. }\end{array}$ \\
\hline 3 & $\begin{array}{l}\text { Formal planning / zoning } \\
\text { phase }\end{array}$ & $\begin{array}{l}\text { Adaptations, land use plan, zoning plan, } \\
\text { building regulation plan, formal steps defined } \\
\text { by law, approval by City Council. }\end{array}$ \\
\hline 4 & $\begin{array}{l}\text { Design and implementation } \\
\text { phase }\end{array}$ & $\begin{array}{l}\text { Final design of buildings, public/green spaces, } \\
\text { adaptations, competition. Building and } \\
\text { environmental permits according to law. }\end{array}$ \\
\hline 5 & Operational phase & Monitoring, district / quarter management \\
\hline
\end{tabular}




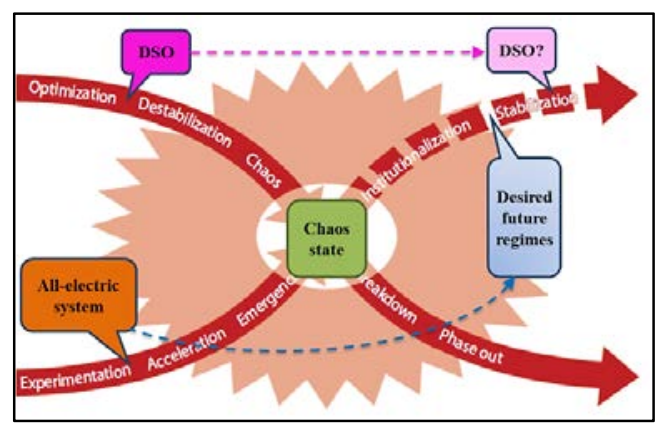

Figure 1: DSO and all-electric system in transition pathways, based on Loorbach.

The energy transition requires a worldwide effort, comprising the development and use of new and innovative technologies, practices and forms of organization [15], This also affects the DSO, which is steadily changing from a passive network operator to an active manager of a smart distribution systems. Fig. 1 is based on a framework [13] that describes the pathways in generic transition processes. The current energy landscape is on the left side, and the unknown future landscape on the right side of the transition process. The DSO's current position is plotted in pink in the upper left stream representing settled institutions and current business. The all-electric system is plotted in orange in the lower left stream, where experiments and innovations or "niches" [14] are developed. The desired future regimes are plotted in blue in the upper right stream, just like the yet unknown role of the DSO in the future regime. The transition of LES can be framed from multi-level perspective (MLP). Interactions between the changing landscape (macro), regime (meso) and niche (micro) levels occur [14], in which the DSO mostly operates where the meso-level meets the micro(household)level.

The assets of the LES includes all physical infrastructure (assets) owned by the DSO: the medium/low voltage transformers and cables from the transformer stations to the houses. It also includes the house owner's hardware in the houses that is used for the conversion of energy into useful energy (like heat and hot water) as well as the transportation of energy into the house (like electricity for household devices) and controlling devices that are connected to the assets (like smart meters).

The current way of designing an energy infrastructure is usually called Network Expansion Planning (NEP). So far, the Dutch NEP practice has been a fit-and-forget approach; after installation the network is not re-evaluated except if problems occur. Very basic information from municipalities on area development is used to estimate numbers and types of connections. Future demand is forecasted mainly by extrapolating historical data; an annual growth of $1-2 \%$ is added to these numbers to provide the base load growth. For most assets (transformers, cables) the depreciation period is 25-30 years [18].

With regard to the scope of this research, two decisions were made. The first decision is the choice for the DSO's perspective. The design, development, realisation and maintenance of the infrastructure of a LES is the DSO's responsibility. Other stakeholders are considered although their specific values are outside the scope of this research. The second decision is that a LES on neighbourhood level was chosen as the geographical area.

Our main research question is: What options has a DSO with regard to its design process in order to better facilitate energy transition? 


\section{METHODOLOGY}

In order to answer the research question, the current and desired DSO design processes in terms of values were assessed. In paragraphs 2.1 and 2.3, the illustrative case study approach and the method of expert interviews are explained, while in 2.2 the value sensitive design method will be described. These research techniques enabled the researchers to investigate how the development and design of a LES currently takes place from a value perspective and how the by DSOs desired design process would look like.

\subsection{Case study description}

The empirical research part consists of a case study on a recently built Dutch neighbourhood that is equipped with individual electric heat pumps. This so-called "all-electric neighbourhood" is an uncommon but growing type of energy system in The Netherlands as it is expected to fully incorporate RES on a local level. The case study was set up together with Enexis, the DSO that operates in the northern part of the Netherlands where the allelectric neighbourhood is situated. For transitions in general, experiments that can accelerate the transition need to be carried out in order to become a part of the desired future regime [13]. An all-electric neighbourhood as an experiment, as plotted in Fig. 1, has the ability to push the energy transition in the right direction. The design process of the energy system was carried out as 'business as usual' in the sense that other stakeholders were not more or less involved in the design process compared to a traditional neighbourhood. The houses in the area can be regarded as representative for future housing stock, with regard to energy efficiency (having energy label $\mathrm{A}+$ and better) as well as having no gas grid connection.

\subsection{Value sensitive design}

The suggested value sensitive design method evaluates and informs (the development of) technologies by considering human values. In this research it is applied to frame the aspects that are relevant for the design of LES. In general, acceptance of a system and satisfaction among stakeholders appear to be higher compared to more traditional methods of design [19]. The difference with methods applied for product and service development is that the value sensitive design method does not solely investigate requirements, but rather takes a broader, multi-disciplinary and more holistic approach.

Two types of values are often distinguished, namely procedural and substantive values. In our case substantive values specifically relate to the all-electric system as an artefact. Procedural values relate to the nature of the rules, regulations and procedures that constitute the decision-making on the design and exploitation of the system. Procedural values have been used in decision-making processes towards the realisation of energy projects in order to improve their quality [10].

The translation of general values into more specific design requirements can be broken down in two steps. The first step is the translation of a general value into one or more general norms. The second step is the translation of these general norms into more specific design requirements. In this research, the translation of values into the norms is carried out for procedural values. As shown in other projects [10], the procedural value of stakeholder involvement that led to higher acceptance was supported by four norms. These norms were applied on our research, scored by the interviewees and are: participation throughout the process, communication, trust between parties and the distribution of costs and benefits. 


\subsection{Expert interviews}

Ten semi-structured interviews were held among ten DSOs and other experts that have experience in working with DSOs from research and business perspective. The experts were asked when and how they and other parties are involved in the design of a LES, and what they desire to do differently with respect to this process. Specific attention was given to the four norms mentioned in 2.2, which they scored on a scale 1-5 in order to indicate the level of importance; 1 represents a low score and 5 a high score. The semi-structured approach was chosen because it provides the required information for analysing current energy system design process. At the same time it gives room for the interviewer and interviewee to discuss topics that might otherwise be overlooked. The data was used to assess categories of values.

In order to analyse the data provided by the interviewees several steps were taken. The data was imported to Atlas.ti software, a qualitative analysis software that allows coding, searching, and retrieving contents of the text. Interviewee's quotations were grouped into the four categories, one interview at a time. Within each category, sub-codes were created based on patterns that emerged from the interviewee's quotations. Finally, data display was used to visually present the relationship between the interviewee's information and codes.

\section{RESULTS}

In this section, the picture of the current and desired design processes is described from the substantive and procedural values' perspective, together with the score on the norms related to the procedural values.

\subsection{Current design process}

Since the operations of DSOs are regulated by the national government, the DSOs operate within the boundaries of reliability of the network on one hand and cost effectiveness on the other hand. On top of this, DSOs must facilitate the growing amount of RES in order to have more sustainable future grids. Traditional Dutch neighbourhoods have a gas and electricity grid. Throughout the years, DSOs have monitored the grids and gathered and analysed energy load data. This has enabled the DSOs to assess the quality of the assets, to plan and carry out maintenance and to better engineer future grids. The case study and interview results were used to get the picture of the current design process.

\subsubsection{Substantive values}

The substantive value "reliability" of the electricity system is two-fold and has its origin in the Network Expansion Planning process as described in the Introduction. The first part is a reliable supply of energy, which consists of the power quality and availability with minimal downtime. The second part is to ensure safety with regard to the grid's components and energy supply.

Design criteria are developed to ensure power quality. For expanding infrastructure, Enexis uses implementation guidelines that specify the number of transformer stations, their capacities and optimal location. Furthermore, they specify the type of the required lowvoltage cables based on the expected load and length of the cables [22]. To simplify the NEP in practice, Enexis uses a number of tables for the connection capacity and design current. E.g. a "traditional" household's design current is 2.4 Ampere and an all-electric household's is 10 Ampere. Design current guidelines may lead to suboptimal solutions for individual cases. However, standardization has benefits like: fast and easy development, clear and 
uniform grid structure and reduction of cost of components due to economies of scale [18]. Worst case scenarios are of the most interest to distribution network planning; situations with maximum generation or maximum load [2]. Distributed generation such as PV solar panels are usually incorporated in the forecasts by using scenarios, whereas the uncertain penetration of new technologies such as heat pumps and electric vehicles are not. Smart grid alternatives in households which lead to less synchronicity and a lower peak of the load are also excluded from NEP practices. To identify bottlenecks for the MV grid, load forecasts are made annually with a time horizon of 10 years. For the case study at hand, Enexis had no experience yet with the type of electric infrastructure, so design criteria were based on theoretical calculations instead of experience. In order to guarantee the same power quality and reliability of the infrastructure compared to traditional neighbourhoods, Enexis overdesigned the grid so that all households have the same design current of $10 \mathrm{~A}$.

The availability can be described as the ability to fulfil the energy demand needed to guarantee the household's comfort level. With the growth of solar panels as well as battery electric vehicles, future synchronicity of the energy load will change. Specifically in an allelectric neighbourhood the synchronicity will be less predictable. Future energy load scenarios would ideally be incorporated in the engineering design in phase 4 of the urban planning.

Safety is covered by the touch safety criterion: faults should be cleared within a predetermined time to ensure people's safety.

To safeguard the reliability DSOs make investment plans with long and short term maintenance activities. The value "affordability" can be split into costs and benefits of the infrastructure from the DSO's perspective. Costs consist of all the invested assets within the boundary of the geographical area. The benefits of the infrastructure are two-fold: a onetime connection fee for realising the grid connection and monthly "standing fees" for maintaining the grids. DSOs apply the financial method of traditional neighbourhoods to allelectric neighbourhoods. Table 2 shows the result of a comparison between the case study all-electric neighbourhood and two different configurations of traditional neighbourhoods. Scenario 1 presents a traditional neighbourhood with only one MV station. Scenario 2 presents the traditional neighbourhood where a second transformer is needed, because the houses are not close enough to be supplied by one transformer. The sum of the cash flows for the all-electric grid only consists of the electricity connection and standing fees. In the sum of the cash flows for scenarios 1 and 2 both the electricity and gas fees are included. These financial benefits exceed the investment costs, so there is a profit per house. The loss per house in an all-electric neighbourhood over the 30-year lifetime of the electricity grid is almost $€ 1,000$ - Under current regulation, these costs are evenly distributed among all Dutch households, independent of the type of connection (all-electric or not) they have. To prevent financial losses per household for the DSO as a result of a growing amount of all-electric neighbourhoods, an increase of connection or standing fees is required. Currently, these fees are standardized and not custom-made nor flexible.

For the value sustainability, several goals are described in the Enexis 2017-year report [24]. One of them is to facilitate residents within a neighbourhood to take energy efficiency measurements as coordinated by the concept of "Buurkracht". It uses the social cohesion and bottom up approach of a group of neighbours to cooperatively invest in house insulation, highly insulated glass or solar panels. Another goal of DSOs as described in the Energieakkoord is to enable the growing amount of RES generated energy to be included in the energy system. To assess sustainability of a certain LES, the $\mathrm{CO}_{2}$ emissions related to the energy generation is calculated. For the case study we applied the national energy mix [9] for this assessment. 
Table 2: Financial comparison of all-electric and traditional scenarios (neighbourhoods).

\begin{tabular}{|l|r|r|r|}
\hline & $\begin{array}{r}\text { All-Electric Grid } \\
\text { (4 transformers, } \\
\text { 165 households) }\end{array}$ & $\begin{array}{r}\text { Traditional Scenario 1 } \\
\text { (1 transformer, } \\
165 \text { households) }\end{array}$ & $\begin{array}{r}\text { Traditional Scenario 2 } \\
\text { (2 transformers, } \\
165 \text { households) }\end{array}$ \\
\hline Investment Costs & $€ 484,087$ & $€ 351,195$ & $€ 448,294$ \\
\hline \hline NPV Cash Flows & $€ 322,365$ & $€ 643,022$ & $€ 643,022$ \\
\hline Net Present Value (NPV) & $-€ 161,722$ & $€ 291,827$ & $€ 194,728$ \\
\hline Profit/Loss Per House & $\mathbf{- € 9 8 0}$ & $€ 1,769$ & $€ 1,180.17$ \\
\hline
\end{tabular}

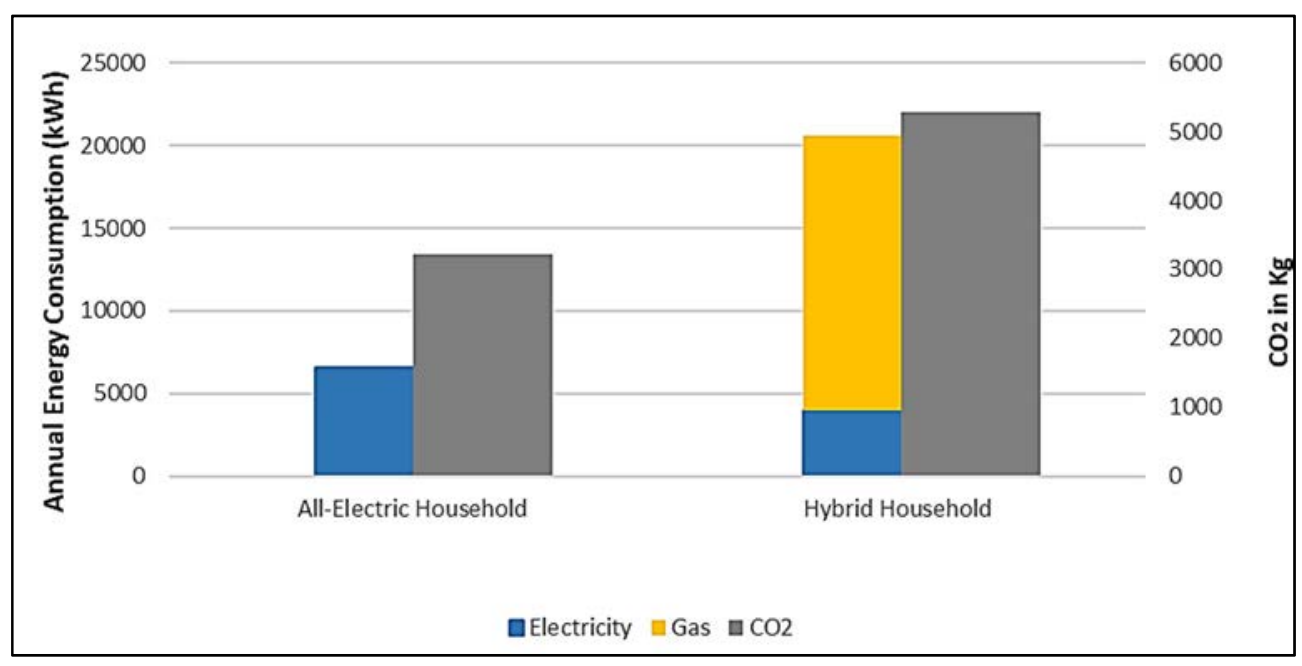

Figure 2: Comparison of all-electric and hybrid households: energy use and $\mathrm{CO}_{2}$ emissions.

This choice is based on the fact that it is not known for each individual household what type of electricity is contracted with the energy supplier: electricity based on RES (or: "green energy") or electricity based on fossil fuels (or: "grey energy"). An average of the case study's households and Dutch hybrid neighbourhood with same energy labels [9] were chosen to base the primary energy use on. Fig. 2 shows the results of this comparison: the $\mathrm{CO}_{2}$ emissions of the case study's average all-electric household is almost $50 \%$ more sustainable than a hybrid household.

\subsubsection{Procedural values}

Procedural values are values that relate to different aspects of stakeholder involvement. From the expert interviews it is evident that design criteria are mainly determined by the DSO. Looking in more detail at this involvement, participation is one of the norms. At this stage, the DSO is often acting alone; all the planning and decision-making regarding what they have to do in order to build or reinforce the grid are hardly communicated with other stakeholders. The DSO occasionally receives information about the total number and type of heat pumps from parties like housing or building companies, real estate developers or municipalities. In 
its year report [24], Enexis notes that they wish to set up a district-oriented approach of new and retrofit neighbourhoods, together with municipalities. However, in practice this appears to be difficult due to the lack of strategic municipal plans. Another reason is that timing is rather unpredictable; progress related to subsidies or permits, local decision making and commitment of residents is crucial. The DSO often designs grids with imprecise or incomplete information for a specific area, despite the fact that the information is known in urban planning phase 2 (feasibility) or phase 3 (planning/zoning). In urban planning phase 4 the DSO cooperates with other companies (e.g. for water, cabling, lighting infrastructure). One of the experts claimed a need at this stage by stating "I think if we do the decisionmaking of the electricity system together, then in the engineering of the households you can make engineering changes, without reinforcing the network. So I suggest to involve building and housing companies in the system design". Stakeholders are supposed to represent the (unknown) future residents of a newly built neighbourhood. However, their interest might differ from the future residents' interest. For example, the real estate developer in the case study was in favour of electric heat pumps instead of a district heating system because financial benefit would be better for him. This benefit resulted in higher initial investment costs for the residents. When it comes to attitude, the interview results show that the general attitude of DSOs is rather passive. Instead of actively seeking for the required information, most DSOs passively wait for other stakeholders to communicate with them.

As the norm of communication between parties concerns, the expert interviews show that there often is a lack of communication and sharing of information between parties, and also between departments within the DSO. One of the DSO experts mentioned "They (the other department) are designing, but we don 't know exactly what it's going to be. We only know how many houses and if its only electricity, but we need to know much more." Limited access to the available information was also mentioned as a drawback in the current design process.

The third value of trust or transparency between parties concerns negative and positive sides of trust. One of the experts that works with the DSO stated, "They could be more transparent, because they tend to be very closed organizations". However, another expert stated, "The level of trust is good in the long experience of working together with each other, so there is no problem." In general, most DSOs are experienced as rather closed organisations instead of being open and transparent.

The last aspect of stakeholder involvement is the distribution of costs and benefits. Specifically, the risks of future energy scenarios that relate to existing houses were mentioned. One of the experts mentioned "The costs are now socialized by all customers, but if some people move off the grid or use a lot less, then the costs are stuck with the people who don't want or are not able to change". The identification of expectations and requirements of stakeholders with regard to financial consequences of future grid choices was often mentioned as necessary for high acceptance of a LES.

\subsection{Desired design process}

Case study and interview results show that substantive values that are part of current practice are the basis for the desired design process. The reliability is covered and regarded as good, but the affordability deserves more attention; the all-electric neighbourhood's investment costs are by far not covered by the income generated with the exploitation of the grid. When it comes to sustainability, the all-electric neighbourhood is desired to be able to incorporate a growing amount of RES so that $\mathrm{CO}_{2}$ emissions can be further reduced. 


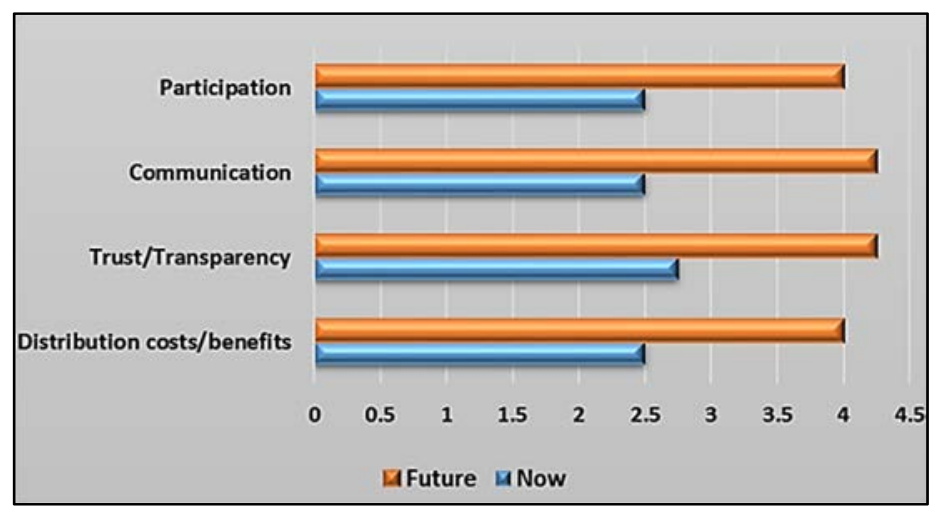

Figure 3: Interviewees' scores on norms with regard to current and future situation.

All interviewees wish to take the four norms related to procedural values into account to a large extent, whereas in the current design process this is done in a limited way. The interviewees were asked to give a score on the norms that relate to the procedural values, in the current and desired future situation, see Fig. 3.

Regarding the second (feasibility) and third (planning) urban planning phases, the experts expressed the need of having more interaction between stakeholders. This is supported by the findings from Edens [1] who by taking a legal approach to investigate several issues between legislations and DSOs, stated that there is a discrepancy between a DSO's intentions and a DSO's daily practices. The fact that DSOs are designing a local energy system mostly by themselves demonstrates that they are holding a passive position. In other words, they still think and act in the traditional way "just tell what to do it and we will do it" and hold a position where they only react when issues arise. However, the norm of participation that should be increased from score 2.5 to 4 showed that it is extremely valuable to take a position of more engagement during earlier stages, especially on a local level. This latter logic is largely defended by Loorbach et al. [13], who state that in a context of dynamic transition, it is required to involve diverse actors in order to have a broader perspective of the sociotechnical regime.

Together with stronger participation of other stakeholders, the need for two-way exchange of information takes place. The desired strengthening of communication from score 2.5 to 4.3 concerns information on substantive values (like criteria that relate to the reliability, affordability and sustainability of the LES) as well as procedural values.

The norm of trust is desired to be 4.3, mainly due to the wish for more openness and transparency from and between the DSO's departments. The distribution of costs and benefits is desired to be 4 , which is regarded as a challenge by most experts. They realise that more sustainable future regimes like the all-electric neighbourhood require higher investment costs.

\section{IMPLICATIONS}

According to the results in the previous section, DSOs are rather satisfied with the way the substantive values are expressed in the current design process, mainly by means of technical design criteria. The main concern is the inevitable increase of connection and/or standing fees related to a growth of all-electric neighbourhoods. This will cause tensions in the affordability of future LES. 
The expert interviews show that the procedural values are only taken into account in an informal way, but not explicitly. The current design process thus has a limited scope, in which there is room for improvement. The procedural values are: participation of stakeholders in the design process, communication between stakeholders, trust and transparency between stakeholders, and the distribution of costs and benefits. DSOs desire a higher degree of involvement of stakeholders at an earlier stage in the design process. Creating a more transparent organisation to build trust among stakeholders and having intensive communication within the organisation and with stakeholders is needed for the DSO to fulfil their role in energy transition. The current standardized and inflexible tariff structure in which costs are socialized, leading to higher fees for households, will be an important topic in the stakeholder involvement.

\section{CONCLUSION AND DISCUSSION}

Based on our analysis, we conclude that the planning and design process of LES is becoming more complex. In order to fulfil its future role, the DSO should take into account four procedural values. With regard to participation, involvement of stakeholders in the design process is required. The DSO should take a more pro-active role instead of a passive attitude in this. As communication concerns, a two-way communication between stakeholders and between DSO departments should be established. Relevant information from phase three and four should then be shared in urban planning phase two. In relation to the trust between parties, a more open attitude of the DSO and other stakeholders is helpful. With regard to the distribution of costs and benefits, we conclude that it is not realistic to assume that the end users are represented by the real estate developer, housing company or municipality. Interests and even values of these parties might differ from the end users' interests, in which case a fully covered value based design and high level of user acceptance is impossible. Experiences and generic values of residents in existing neighbourhoods can be applied to the development of a new LES. Early stakeholder involvement to discuss the topic of costs and benefits distribution is needed to create a high level of acceptance and to relate to the values of reliability and sustainability. Current financial structure is not suitable to incorporate a growth of innovations, like the all-electric neighbourhood. The tariff structure shows a high standardization and is not flexible. Design currents are standardized per type of household and are assumed not to vary in the decades after construction of the houses and the grids. To be able to facilitate future energy loads on the grid, the DSO would preferably anticipate on the development of future LES. This implies a higher flexibility in the design of the LES which includes a flexible tariff structure.

In future, the DSO might be allowed by law to provide other services, such as demandside management and electric vehicle charging. But these roles might also fall under a third party. Either way, an exploration of fulfilment of this role is suggested.

This study was carried out with the results of a case study on a recently built all-electric neighbourhood. A high acceptance of LES is an urgent matter, since many existing neighbourhoods will be retrofitted from a hybrid infrastructure to an energy system without natural gas. In case an all-electric option including electric heat pumps is considered, this study is highly applicable. In case another option is considered, e.g. district heating, generic insights and results that concern the procedural values are applicable, whereas the substantive values are less applicable.

Further research is suggested on other stakeholders' values, specifically the end users. In order to reach a high level of user acceptance, their values should be investigated and incorporated in the complete value-based design approach of a DSO. 


\section{ACKNOWLEDGEMENTS}

The researchers thank the colleagues from the Centre of Expertise Energy of Hanze University of Applied Sciences who contributed to this article. The researchers also highly appreciated the time and effort that the interviewees spent on the interviews.

\section{REFERENCES}

[1] Edens, M., Public value tensions for dutch DSOs in times of energy transition: A legal approach. Competition and Regulation in Network Industries, 2018, pp. 132-149, 2017.

[2] Veldman, E., Gibescu, M., Slootweg, H. \& Kling, W., Impact of electrification of residential heating on loading of distribution network. IEEE, pp. 1-7, 2011.

[3] Geels, F., Technological transitions as evolutionary reconfiguration processes: A multi-level perspective and a case-study. Research Policy, 31(8-9), pp. 1257-1274, 2002.

[4] ECN and Energie-Nederland and Netbeheer Nederland. Energietrends 2016, ECN and Energie-Nederland and Netbeheer Nederland, 2016.

[5] United Nations / Framework Convention on Climate Change, Paris Agreement, United Nations, 2015.

[6] Social-Economische Raad, Energieakkoord voor duurzame groei, SER, Den Haag, 2013.

[7] Longo, D., Boeri, A., Gianfrate., V., Palumbo, E. \& Boulanger, S.O., Resilient cities: Mitigation measures for urban districts. A feasibility study. Sustainable Development and Planning, 13(5), pp. 734-745, 2018. DOI: 10.2495/sdp-v13-n5-734-745.

[8] Ministry of Economic Affairs and Climate, Besluit van 26 april 2018 tot vaststelling van het tijdstip van inwerkingtreding van de Wijziging van de Elektriciteitswet 1998 en van de Gaswet (voortgang energietransitie). Staatsblad van het Koninkrijk der Nederlanden, 129, pp. 1-4, 26 Apr. 2018.

[9] Central Bureau of Statistics in The Netherlands. Online. www.cbs.nl, http://statline.cbs.nl/statweb.

[10] Dignum, M., Correlje, A., Cuppen, E., Pesch, U. \& Taebi, B., Contested technologies and design for values: The case of shale gas. Science and Engineering Ethics, pp. 1171-1191, 2016.

[11] Bozeman, B., Public Values and Public Interest: Counterbalancing Economic Individualism, Georgetown University Press: Washington, 2007.

[12] Urban Learning, Urban Learning. Online. www.urbanlearning.eu/toolbox/planningprocess/. Accessed on: 31 May 2018.

[13] Loorbach, D., Frantzeskaki, N. \& Avelino, F. Sustainability transitions research: Transforming science and practice for societal change. Annual Review of Environment and Resources, 2017.

[14] Geels, F., Technological transitions and system innovations: A co-evolutionary and socio-technical analysis. Edward Elgar, 2005.

[15] International Energy Agency, World Energy Outlook 2016, Paris, 2016.

[16] Ministry of Economic Affairs, Energieagenda, Ministry of Economic Affairs, Den Haag, 2016.

[17] Leeuwis, C. \& Van Den Ban, A., Communication for Rural Innovation: Rethinking Agricultural Extension, Blackwell Science: Oxford, 2004.

[18] Bernards, R., Morren, J. \& Slootweg, J., Incorporating the smart grid concept in network planning practices. 50th Universities' Power Engineering Conference, 2015. 
[19] Manders-Huits, N., What values in design? The challenge of incorporating moral values into design. Science and Engineering Ethics, 17(2), pp. 271-287, 2011. DOI: 10.1007/s11948-010-9198-2.

[20] Correljé, A., Cuppen, E., Dignum, M., Pesch, U. \& Taebi, B., Responsible innovation in energy projects: Values in the design of technologies, institutions and stakeholder interactions. Responsible Innovation 2: Concepts, Approaches, and Applications, Springer International Publishing, pp. 183-200, 2015. DOI: 10.1007/978-3-31917308-5 10.

[21] Poel, I.V. ., Philosophy and Engineering: Reflections on Practice, Principles and Process, Springer Netherlands: Dordrecht, pp. 253-266, 2014.

[22] Enexis. Implementatie LS-Kaders, 2015.

[23] Persson, T. \& Broberg, L., Is our everyday comfort for sale? Preferences for demand management on the electricity market. Energy Economics, 54, pp. 24-32, 2016. DOI: 10.1016/j.eneco.2015.11.005.

[24] Enexis Holding NV. Enexis Jaarverslag 2017, Enexis Holding NVs-Hertogenbosch, 2018. 